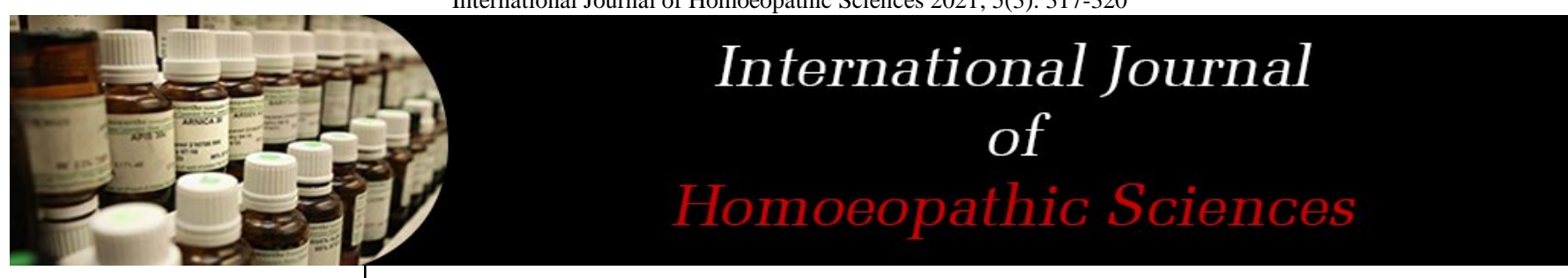

E-ISSN: $2616-4493$

P-ISSN: 2616-4485

www.homoeopathicjournal.com IJHS 2021; 5(3): 317-320

Received: 09-05-202

Accepted: 11-06-2021

Dr. Lokesh Pradeep Mantri

P.G. Scholar Gurumishri

Homoeopathic Medical College

Shelgaon, Maharashtra, India

Dr. Anagha Beedkar

P.G. Guide Gurumishri

Homoeopathic Medical College

Shelgaon, Maharashtra, India
Corresponding Author: Dr. Lokesh Pradeep Mantri P.G. Scholar Gurumishri Homoeopathic Medical College Shelgaon, Maharashtra, India

\section{Need to utilisation homoeopathic management in polycystic ovarian syndome}

\author{
Dr. Lokesh Pradeep Mantri and Dr. Anagha Beedkar
}

DOI: https://doi.org/10.33545/26164485.2021.v5.i3e.441

\begin{abstract}
polycystic ovarian syndrome is an endocrine disorder is an endocrine disease which affect $4 \%$ of female where incidence increase day to day life where homoeopathy can answer safely without holistic approach homoeopathy treatment has no side effect homoeopathy literature making that most similimum medicine keep away from disease .evidence of homoeopathic medicine safe \& gentle which is cost effective a main benefit of homoeopathic management is cost effective in fertilisation \& no need surgical resection [11] some homoeopathic medicine which play most important role which shows certain evidence also to their curative action these medicine are 1] Lycopodium 2] Pulsetila 3] Conium Mac 4] Iodum 5] Apis Mellifica 6] Sepia 7] Calceria Carb 8] Calceria Flu with the help of correct similimum get miracle like cure in PCOS.
\end{abstract}

Keywords: PCOD, women, hyper androgen, obesity, hyperinsulinemia, amenorrhoea, LH, homoeopathy, rubric, reparatory

\section{Introduction}

Polycystic ovarian syndrome is common endocrine disorder predominantly affecting women of reproductive age Polycystic ovarian syndrome ${ }^{[3]}$ first time described was first time described by Stein \& Leventhal mainly consist of amenorrhoea, hirsutism, \& obesity associated with enlarged polycystic ovary. This disorder mainly characterized by excessive androgen production in ovary. Diagnosis based in any 2 following 3 criteria. 1]

1. Oligo \& /or anovulation

2. Hyper androgenism - clinical or biochemical.

3. Polycystic ovary with other Hormonal aetiology [CAH, thyroid dysfunction, hyperprolactinemia, Cushing syndrome ${ }^{[1]}$

Over all total incidence in PCOS is $0.5-4 \%$ total female ${ }^{[1]}$ in world.in India prevalence of PCOS 3.7-22.5\% ${ }^{[3]}$ Current incidence of PCOS [5-6\%] ${ }^{[2]}$ increases it is due to change lifestyle \& stress. now a days it is most common problem adolescent female. \& also postmenopausal women in India. Overall total infertile female $20 \%$ infertility cause due to PCOS which later complication like cardiovascular disease, Hypertension, endometrial cancer \& type 2 diabetics later in life.

1. In female due to PCOS change in life style diet, \& stress commonest cause are change in endocrine pattern 2] Genetic 3] Familial environment factor ${ }^{[2]}$.

2. CYP21 gene mutation also a one cause ${ }^{[2]}$.

3. Serine phosphorylation unification activity [hyper androgen] \& reduce insulin receptor activity seen in ovary ${ }^{[2]}$.

4. Obesity is an effect of endocrine \& immunomodulatory organ which secrete leptin, adiponectin, \& cytokines which interfere with insulin signalizing pathway in the liver \& muscle resulting insulin resistance \& hyperinsulinemia ${ }^{[2]}$.

5. Increase LH secretion by insulin can cause infertility. Also an effect of miscarriage.

6. Hyper androgen also effect of anovulation ${ }^{[1]}$

7. Hyper insulenimia initiates PCOS where adrenal \& hypothalamus-pituitary -ovary involved certain axis. Where insulin induces LH cause thecal hyperplasia \& secrete androgen ${ }^{[1]}$.

Pathophysiology in disease- in PCOD ovaries are enlarged. volume of ovary is increased by $10 \mathrm{~cm} /$ cube Stroma increase capsule are thick \& white colour with presence of multiple follicular cyst more than 12 average measuring in range between 2-9mm in diameter are crowded around the cortex ${ }^{[1]}$. 
Histologically disease is manifested by thickening of tunica albuginea. The cyst are follicles at varying stages of maturation \& atresia. there is theca cell hypertrophy [stromal hyperthecosis] ${ }^{[1]}$.

Hormonal changes in PCOS- 1] LH level elevated \& the ratio of $\mathrm{LH}$ : FSH IS $>2: 1^{[1]}$

1. Increase level of estradiol ${ }^{[1]}$.

2. Hyperandrogenism mainly by ovary not adrenal [ovary \& adrenal both secreted androgen]. Ovary produce maximum androgen due to stimulation of theca cell by high LH here P450 C17 enzyme hyper function ${ }^{[1]}$.

3. Raised serum testosterone \& DHEA may be marginally elevated ${ }^{[1]}$.

4. Raised fasting insulin level $>25 \mu \mathrm{IU} / \mathrm{mL} \&$ Fasting insulin glucose level less than $<4.5^{[1]}$.

\section{Hormonal schematic presentation in PCOS ${ }^{[1]}$ \\ Scheme 1}

hypothalumus $\rightarrow$ increased pulse frequency of $\mathrm{GnRH} \rightarrow$ pituitary sensitive to $\mathrm{GnRH} \uparrow \rightarrow$ increased pulse frequency of LH [preferential] $\rightarrow$ compared to FSH $\rightarrow$ LH $\uparrow:$ FSH $\downarrow$ Here estradiol \& androgen $\uparrow$ in positive feedback while estradiol $\uparrow$ in negative feed back mechanism ${ }^{[1]}$.

\section{Scheme 2 [ovary]}

$\mathrm{LH} \uparrow$ insulin $\uparrow$ androgen $\uparrow \quad \mathrm{IGF}-1 \uparrow \quad \mathrm{P} 450 \quad \mathrm{C} 17$ enzyme dysregulation $\downarrow$ Aromatization ---these all changes done in ovary ${ }^{[1]}$.

\section{Scheme 3 [ovary]}

Androgen $\uparrow \rightarrow$ peripheral Aromatization $\rightarrow$ SHBG $\downarrow \rightarrow$ Unbound E2 $\uparrow \rightarrow$ Tonic hyperestrogenic state $\rightarrow$ pitutury sensitive to $\mathrm{GnRH}{ }^{[1]}$.

\section{Scheme 4}

FSH $\downarrow \rightarrow$ [granulosa cell, theca cell, stroma cell] $\rightarrow$ LH $\uparrow$ IGF- $1 \uparrow$ androgen $\uparrow \rightarrow$ follicular maturation $\downarrow$ Aromatization $\downarrow$ lead to E2 decreases \& inhibin increases ${ }^{[1]}$.

\section{Scheme 5 [OBESITY]}

Obesity - $\rightarrow$ insulin $\uparrow$ insulin resistance $\uparrow \rightarrow$ effect on liver $\rightarrow$ SHBG $\downarrow$ IGFBP $\downarrow$ androgen $\uparrow$

IN OVARY theca cell- androgen $\uparrow^{[1]}$.

Table 1: Hormonal changes in PCOS [4]

\begin{tabular}{|c|c|}
\hline Hormone increased & Hormone decreased \\
\hline Androgen [testosterone, andosterone, DHEAS] & FSH \\
\hline Luteinizing hormone LH > 10 IU/ML & Progesterone due to anovulation \\
\hline \multicolumn{2}{|c|}{ ESTROGEN \& total free oestrogen } \\
\hline Insulin > 10 ml IU/L due to insulin resistance & Sex hormone binding globulin \\
\hline Prolactin in some patient & HDL \& Apoprotein A-L \\
\hline \multicolumn{2}{|c|}{ LDL/Cholesterol \& triglyceride } \\
\hline
\end{tabular}

\section{Clinical feature-}

1. Oligo menorrhoea done in $87 \%$ or with a short period of amenorrhoea noted $26 \%$ followed by a prolonged heavy period. Where dysmenorrhoea is absent ${ }^{[2]}$.

2. Infertility is due to an ovulatory cycle $20 \%$ cases noted where pregnancy loss occur $20-30 \%$ cases ${ }^{[2]}$.

3. Effect of hyperandrogenism acne $30 \%$ \& hirsutism especially on upper lip, chin, breast, \& thigh \& also baldness noted ${ }^{[2]}$.

4. In past history life style, diet, smoking, find out where family history diabetis \& hypertension also find also rule out excessive exercise history of tuberculosis \& thyroid are important ${ }^{[2]}$.

5. Hyperinsulenimia mostly associated with acanthosis nigra $5 \%$ over the nape of neck axilla \& below the breast $^{[1]}$.

6. Differential diagnosis- 1] congenital or adult hyperplasia. 2] Cushing disease. 3] Ovarian muscular tumor.4] obeys women with virilism. 5] Thyroid Hormone dysfuction ${ }^{[1,2]}$.

\section{Investigation}

1. Ultrasound a] ovarian scan- volume of ovary is increased by $10 \mathrm{~cm} /$ cube. Multiple follicular cyst more than 12 average measuring in range between $2-9 \mathrm{~mm}$ in diameter are seen in PCOS. b] Also rule out ovarian tumour, endometrial hyperplasia. C] Also use to rule out adrenal hyperplasia or tumour ${ }^{[1,2]}$.

2. Thyroid function test in obeys women- ${ }^{[1,2]}$
3. Laparoscopy clear diagnosis \& also use for therapeutic evaluation or procedure.

4. Oligoamnorrhoea history this symptom is most important in diagnosis ${ }^{[1,2]}$.

5. Testosterone level that is total testosterone \& free testosterone level increase while decrease in SHBG level ${ }^{[5]}$.

6. Elevated LH: FSH ratio may be occur but not longer time while rise physiological LH level during LH surge [5].

\section{Complication}

1. An ovulatory PCOS lead to more chance of endometrial hyperplasia \& endometrial cancer also because of high oestrogen \& low progesterone level ${ }^{[5]}$.

2. Hyperinsulinemia with insulin resistance lead to increased risk of diabetes mellitus ${ }^{[5]}$.

3. Mostly PCOS women are obeys obeys women with insulin resistance increase chance of hypertension \& cardiovascular disease ${ }^{[5]}$.

\section{Homoeopathic management from some famous repertory}

Homoeopathy is evidence based pathy recently some evidence based study shows nicely treated case of PCOS in which medicine select with individualisation \& totality of symptom. Some best homoeopathic drug which play most important role. According to kent reporetory we find following rubric according to disease totality 
Table 2: Kent repertory ${ }^{\text {[12] }}$

\begin{tabular}{|c|l|c|c|c|c|c|}
\hline Rubric & Find in chapter & Lycopodium & Conium mac & Iodum & Apis mellifica & Lachesis \\
\hline Menses absent amnorrhoea & Genitalia Female & 3 & 3 & 2 & 2 & 2 \\
\hline Menses irregular & Genitalia Female & 2 & 2 & 2 & 2 & 2 \\
\hline Cyst & Genitalia Female & & & & & \\
\hline Enlarged swollen ovary & Genitalia Female & 2 & 3 & 2 & 3 & 1 \\
\hline Tumors of ovary & Genitalia Female & 3 & & 2 & 3 & 3 \\
\hline Induration gland & Genralitis & 2 & 3 & 3 & - & - \\
\hline Swollen gland & Genralitis & & 1 & & & 1 \\
\hline Sycosis & Genralitis & 2 & 1 & 2 & 2 & 2 \\
\hline Hair unussal part & Skin & & & & & \\
\hline & & $14 / 6$ & $13 / 6$ & $13 / 6$ & $12 / 6$ & $11 / 6$ \\
\hline
\end{tabular}

Table 3: Phatak Reparatory ${ }^{\text {[12] }}$

\begin{tabular}{|c|c|c|c|c|c|c|}
\hline Phatak reporetory ${ }^{[\mathbf{1 , 2}]}$ Rubric & Find in chapter & Pulsetila & belladona & Calceria & lycopodium & Sulpher \\
\hline Ovary cystic & Phatak A-Z & & & & 1 & \\
\hline Ovary swelled & Phatak A-Z & & 1 & & 1 & 1 \\
\hline Obesity & Phatak A-Z & 1 & 1 & 3 & & 2 \\
\hline Menses disturbances of[ in general] & Phatak A-Z & 3 & 3 & 2 & & 2 \\
\hline $\begin{array}{c}\text { Menses disturbance amenorrhoea } \\
\text { Menses absent, suppresed }\end{array}$ & Phatak A-Z & 3 & 1 & & 2 & \\
\hline Hair chin \& upper lip on women & Phatak A-Z & & & & & 2 \\
\hline Gland in general & Phatak A-Z & & & 3 & 2 & 1 \\
\hline & & $10 / 4$ & $8 / 5$ & $8 / 3$ & $6 / 4$ & $6 / 4$ \\
\hline
\end{tabular}

Table 4: Boning Hussain Reporetory ${ }^{[12]}$

\begin{tabular}{|c|c|c|c|c|c|c|}
\hline Rubric & Find in chapter & lycopodium & Pulsetilla & Sepia & Belladonna & Conium mac \\
\hline Menses absent amenorrhoea & Menstruation & 1 & 4 & 1 & & 1 \\
\hline Menses too late & Menstruation & 4 & 4 & 4 & 1 & 3 \\
\hline Gland hard indolent & Gland & & & & & \\
\hline Gland induration nodes & Gland & 3 & 3 & 1 & 4 & 4 \\
\hline Ovaries & Genitalia female & 3 & 1 & 3 & 4 & 3 \\
\hline Female organ swollen & Genitalia female & 4 & 1 & 3 & 3 & \\
\hline Hair increased growth on odd part & Skin \& ex terior part & 1 & & & & \\
\hline
\end{tabular}

Above all three standard repertory after repatriation observed that most commonest drug for PCOD IS .homoeopathy approach in PCOD holistic approach homoeopathy treatment has no side effect homoeopathy literature making that most similimum medicine keep away from disease .evidence of homoeopathic medicine safe \& gentle which is cost effective a main benefit of homoeopathic management is cost effective in fertilisation \& no need surgical resection ${ }^{[11]}$.

1] Lycopodium 2] Pulsetila 3] Conium Mac 4] Iodum 5] Apis Mellifica 6] Sepia 7] Calceria Carb 8] Calceria Flu

According to totality of symptom medicine may change if patient having other symptom`s

1. Lycopodium-burning \& stitching pain in ovary complain relived after urination sharp shooting pain extend from right to left menses too late too profuse dry ness of whole female genital track ${ }^{[6]}$. Right sided ovary polycystic act specially keen intelluctal but physically so weak. Pain in abdomen \& uterine region lycopodium Dr Kent has cured many cases of cystic tumor of ovary absent or supparation of menses is key feature of lycopodium ${ }^{[7]}$.

2. Pulsetilla-this is first homoeopathic remedy for menstrual supparation amenorrhoea with anemia. Cystic ovary.[8] Mostly suited to slow phlegmatic women .derangement at puberty menses are too late scanty get wet too faint ovarian abdominal pain aggravated by in warm room while ameliorated in open air [9].

3. Apis mellifica - ovaritis with soreness in the inguinal region burning, stinging \& tumefaction at ovarian region Ovarian cyst in their incipiency numbness down the thigh usually left ovary may affected ${ }^{[6]}$. serous inflammation at ovary pain in right ovary with pain inpectoral region. Ovaritis with amenorrhoea ovarian tumor with ovarian dropsy. Ovary enlarge, swollen \& indurated pain aggravated by touch \& heat.

4. Conium mac-induration \& enlargement of ovary Atropy of ovary with sterility. Ovarian affection with amenorrhoea. PCOD with hyperinsulinemia with diabetis are more marked mostly suited this remedy to old people with looking rigid muscular fibre. Atropy of ovary with sterility. Mostly suited to cancerous scrofulous person enlarged gland glandular induration of stony gland especially to mammary gland breast sore hard tender \& painful. Prostatic or uterine affection, menses feeble too late scanty. Leucorrhoea 10 days after menses. Bad effect of supressed menses ${ }^{[9]}$.

5. Iodum- ovarian cyst with dropsy great breathing pain Induration \& enlargement of gland pain coming right ovary passing down wedge like pain from ovary toward the uterus pain in ovary \& back toward the menses great sensitive to right ovary during \& after menses. Yellow corrosive leucorrhoea sallow tawny like [6] person with profund debility Hypertropy \& induration of Glandular tissue, thyroid, mamma, ovaries mostly complain aggravated in warmth ${ }^{[9]}$. 
6. Sepia- mostly suited to dark hair rigid fibre but mild \& decomposition specially a remedy for disease of women washer women complain aggravated by laundry work sensation as if ball feeling in inner organ like uterus \& ovary sexual organ weak \& exhausted irregular menses early or late scanty profuse amenorrhoea or menorrhagia stitching pain in lower abdomen itching at female external genitalia ${ }^{[6]}$.

7. Nux moschata- mostly suited to women hysterical temperament oversensitive to all impression every menstruation dryness present all over body leucorrhoea instead of menses in old days it use for beginning of menstrual period.

8. Calceria carb- chief action of this remedy specially gland bone, \& skin swelling of gland scrofulous abscess in deep muscle especially smooth muscle ovary uturus along with ovarian cyst. Best remedy for pituitary \& thyroid dysfunction. Leucorrhoea milky white in colour mamma hard swollen \& painful Menses too early to profuse too long all the abnormality is form endocrine derangement ${ }^{[10]}$.

9. Calceria flu- Hard stony gland especially all endocrine gland like pituitary, thyroid, adrenal \& ovary Hard knot in female brest.

\section{References}

1. Datta DC. Text Book of Gynecology including contraception .New Delhi: Jaypee Brother Publisher $6^{\text {th }}$ edition 2013

2. Padubidri VG, Daftary SN. Howkins \& Bourne shaw`s Text Book Of Gynecology $16^{\text {th }}$ edition. Elsevier a division of Elsevier India private Limited,[N.D.]

3. www.ncbi.nlm.nih.gov /pmc/article/PMC6902362/ serch on google scholar

4. Arora Sakshi \& Hans Jaypee self Assesmet \& Review Of Gynecology $9^{\text {th }}$ edition New Delhi Jaypee health science publisher,[n.d.]

5. M Bain, Catrina, Kevin Burton C. Jay Mcgavigan Gynecology Illustrated $6^{\mathrm{TH}}$ edition Elsevier churchil living stone,[n.d.]

6. Lilienthal, Samuel. Homoeopathic Therapeutic. New Delhi: B Jain publisher pvt ltd., 2004.

7. Kent, James Tylor. Lectures on homoeopathic materia medica .New Delhi: Introduced Jugal Kishore B Jain Publisher,[n.d.]

8. Dewey WA. Practical Homoeopathic therapeutic. New Delhi: B Jain Publisher, 2002.

9. Allen H. keynotes and characteristics with comprenson of some of the leading remedies of the materia medica. $8^{\text {th }}$ edition New Delhi: B. Jain Publisher [p] Ltd.

10. Boericke W. Pocket Manual of Homoeopathic material medica and reparatory $.9^{\text {th }}$ edition New Delhi: B. Jain Publisher [p] Ltd.

11. www.ijrh.org/article asp?issn=09747168; year $=2018$; volume $=12$;issue $=2$; spage95; epage $=10$ 0 ; aulast $=$ rath;type $=3$

12. Homoeopath firefly a android software by $\mathrm{Dr}$ Jawaharlal Shah 